\title{
Shielding Effectiveness of Electromagnetic Field by Specially Developed Shielding Coating
}

\author{
I. Kolcunováa ${ }^{a}$, J. ZBojovskÝ ${ }^{a}, *$, M. Pavlík ${ }^{a}$, S. Bucko ${ }^{b}$, J. LABun $^{b}$, M. Hegedus $^{c}$, \\ M. VAvra ${ }^{c}$, R. Cimbala ${ }^{a}$, J. KurimskÝ ${ }^{a}$, B. Dolník ${ }^{a}$, J. Petrás̆ $\check{S}^{a}$ And J. DŽmura ${ }^{a}$ \\ ${ }^{a}$ Dept. of Electric Power Engineering, Faculty of Electrical Engineering and Informatics \\ of the Technical University of Košice, Mäsiarska 74, 041 20, Košice, Slovakia \\ ${ }^{b}$ Dept. of Avionics, Faculty of Aeronautics, Technical University of Košice, Rampová 7, 04121 Košice, Slovakia \\ ${ }^{c}$ Institute of Chemistry, Faculty of Science, P.J. Šafárik University in Košice, SK-040 01 Košice, Slovakia
}

This article aims to present the results of the measurements of the electromagnetic wave penetration through the building element with a specially developed shielding coating. Shielding coating represents dispersed powder in semiconducting liquid. The powder consists of the complex oxides of $\mathrm{La}_{0 .} \mathrm{Sr}_{0.3} \mathrm{MnO}_{3}$ (LSMO), $\mathrm{ZnFe}_{2} \mathrm{O}_{4}, \mathrm{NiFe}_{2} \mathrm{O}_{4}$ composition and were prepared by self-combustion method using corresponding metal nitrates in required molar ratio and glycine as fuel. Measurements were made for powder concentration of $5 \mathrm{~g}$. Measurements were performed in the frequency range from $0.8 \mathrm{GHz}$ to $8 \mathrm{GHz}$. The measurement results show the electromagnetic wave shielding effectiveness of the used shielding coating.

DOI: 10.12693/APhysPolA.137.711

PACS/topics: shielding coating, experimental powder electromagnetic field, high frequency, reflection absorption, shielding effectiveness

\section{Introduction}

Electric lines, mobile phones, computers, radio and TV transmitters, and many other sources of electromagnetic waves produce an unhealthy environment $[1,2]$. These types of devices cause electromagnetic pollution. The term electrosmog refers to all electromagnetic waves surrounding our environment. The amount and type of radio waves and microwaves in the environment is increasing every year. The presence of electromagnetic interference (EMI) signals, which sometimes overlap in the frequency spectrum has been causing problems for television and radio broadcasting, military, aerospace, and medical applications. Many scientists are focusing on the development of materials and elements that have the capability to prevent the penetration of electromagnetic waves. One of the possibilities to protect human health from electrosmog is to prevent the penetration of electromagnetic waves from the external environment into the indoor environment of buildings. Glass windows, roofs, specially developed bricks, and shielding coatings on the outer and inner walls of buildings are used for this purpose [1].

\section{Preparation of the shielding coatings}

Inspiration for this experiment are a few previous published research works developing shielding coatings [2-4]. In the experiment the complex oxides were used with

\footnotetext{
*corresponding author; e-mail: jan.zbojovsky@tuke.sk
}

Thomsit conductive coating applied on the material from sololit. The complex oxides $\mathrm{La}_{0.7} \mathrm{Sr}_{0.3} \mathrm{MnO}_{3}$ (LSMO), $\mathrm{ZnFe}_{2} \mathrm{O}_{4}, \mathrm{NiFe}_{2} \mathrm{O}_{4}$ were prepared by self-combustion method using corresponding metal nitrates in required molar ratio and glycine as fuel. The powder X-ray diffraction patterns of the annealed samples revealed the presence of single phase. The $\mathrm{La}_{0.7} \mathrm{Sr}_{0.3} \mathrm{MnO}_{3}$ complex oxide crystallizes in rhombohedral $R-3 c$ space group. On the other hand, the complex oxides, both $\mathrm{ZnFe}_{2} \mathrm{O}_{4}$ and $\mathrm{NiFe}_{2} \mathrm{O}_{4}$, crystallize in the cubic $F d-3 m$ space group of magnetite-like structure. The mean values of atomic percentage of the metals measured by energy dispersive X-ray analysis $(\mathrm{EDX})$ are $\mathrm{La}: \mathrm{Sr}: \mathrm{Mn}=0.64: 0.26: 1$ for $\mathrm{La}_{0.7} \mathrm{Sr}_{0.3} \mathrm{MnO}_{3}, \mathrm{Zn}: \mathrm{Fe}=1: 2.22$ for $\mathrm{ZnFe}_{2} \mathrm{O}_{4}$, and $\mathrm{Ni}: \mathrm{Fe}=1: 1.99$ for $\mathrm{NiFe}_{2} \mathrm{O}_{4}$ and show a little deviation from the starting metal ratios. Metal nitrates were prepared from non-hygroscopic precursors: $\mathrm{La}_{2} \mathrm{O}_{3}$, powder metals $\mathrm{Mn}, \mathrm{Zn}, \mathrm{Fe}$ and $\mathrm{Ni}(\mathrm{OH})_{2}$. These precursors were dissolved in diluted nitric acid to form corresponding nitrates. Only strontium nitrate was used as metal containing starting material. The molar amount of glycine was set as $50 \%$ to the total nitrates molar amount. Solutions containing metal nitrates and glycine were heated to dehydrate until they became a viscous gel. On a hot plate, the viscous gel autoignited automatically and after short combustion, black porous ashes were formed. All as prepared samples were annealed at $800^{\circ} \mathrm{C}$ for $1 \mathrm{~h}$.

\section{Shielding effectiveness, reflection, and absorption of electromagnetic field}

Quality of shielding materials are determined by three coefficients, shielding effectiveness SE, absorption 
coefficient $A$, and a reflection coefficient $R$. The shielding effectiveness $\mathrm{SE}$ is closely related with coefficients $R$ and $A$. The absorption coefficient $A$ is given as $[5,6]$ :

$$
A=8.69 \frac{t}{\sqrt{\frac{2}{\omega \mu \sigma}}},
$$

where $t$ is the thickness of shielding material, $\delta$ is the depth of electromagnetic penetration into the material, $\mu$ is permeability which includes the permeability of shielding material, $\sigma$ is a unit of conductivity of shielding material. The coefficient of reflection $R$ is given as

$$
R=20 \log \left(\frac{1}{4} \sqrt{\frac{\sigma}{\omega \mu_{R} \varepsilon_{0}}}\right),
$$

where $\mu_{R}$ is permeability of shielding material, $\varepsilon_{0}$ is permittivity of vacuum, and $\sigma$ is electrical conductivity. From (1) and (2) we can see that the shielding effectiveness depends on material properties.

\section{Measurement method and results}

The measurement method was based on the patented experimental method for depolarisation vector of the electromagnetic field intensity. A high-frequency signal was depolarised by a depolarisation grid and subsequently it was divided into two components: a reflected component by grid and a continuing vector through a dielectric layer with a phase shift of $90^{\circ}$. Furthermore, the continuous vector in dielectric is reflected by a conductive metal plate back to the polarisation grid, and then it is depolarised again. As the second depolarisation divided the reflected vector from the iron plate with the same analogy as before, both the reflected signal before the polarisation and the signal from the second polarisation in front of the panel were summed together. The results of this phenomenon are the following:

- Change of the vector polarisation of intensity HF field by $45^{\circ}$;

- Change of the phase of HF signal by $180^{\circ}$;

- HF signal time delay by $\lambda / 2$.

Detailed description and analogy of depolarisation panel can be found in [7] and [8].

The depolarisation panel for determining the reflection and the absorption component of the samples was used in this work. The examined sample was composed of a powder of different particles mixed with a basic commercial conductive paint (Thomsit) and then it was applied on a base pressboard by a paint-roller. The sample thus prepared was placed in front of the depolarisation panel.

The measurement assembly was made up of two funnel antennas ETS Lindgren, model 3115 with frequency band $800 \mathrm{MHz}-8 \mathrm{GHz}$, coaxial cables and a VNA analyser Rohde \& Schwarz FSH8. This measurement assembly was placed into a fully anechoic chamber Frankonia CHC. Scatter parameter S21 was measured by the VNA analyser. For the reflection parameter the antennas were

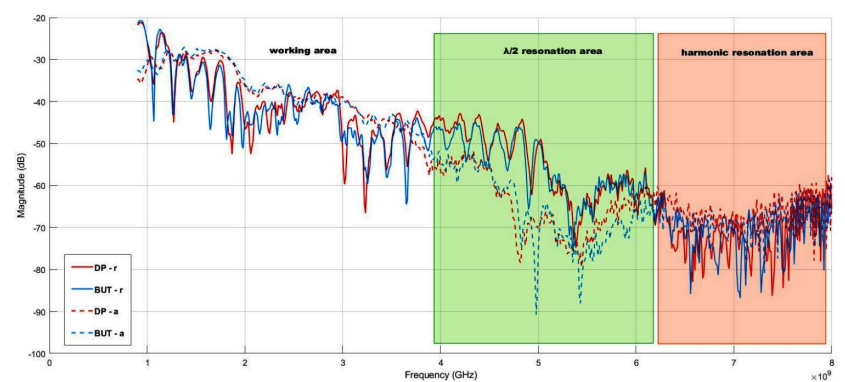

Fig. 1. Reflection and the absorption behaviours of the depolarisation panel.

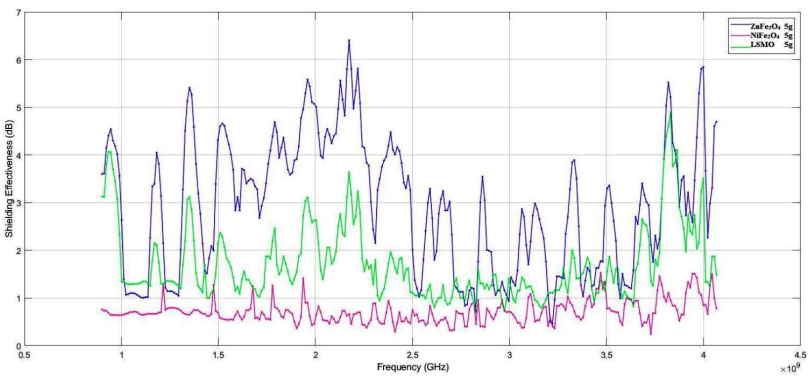

Fig. 2. Shielding effectiveness of experimental coatings.

in the same horizontal positions and in case of absorption measurement the receiving antenna was rotated by $90^{\circ}$ (into the vertical position). Figure 1 shows the reflection and the absorption behaviours of the depolarisation panel compared with basic painted board without any powder. We can observe three areas in frequency spectrum, which had been defined based on the practical measurements and they depend on dimensions of the panel, diameter of the wires in depolarisation grid, and distance between the panel and the antennas. The work area was defined in frequency band from $900 \mathrm{MHz}$ to $4 \mathrm{GHz}$ where it is not considerably influenced by the phase shifting and the dispersion of the values. For the specification of the difference between the base painted board and the boards with powder, a method was used where values of the basic board had been subtracted from the board with powders.

Figure 2 shows the shielding effectiveness of experimental coatings. The shielding coating was prepared by mixing $5 \mathrm{~g}$ of powder with conductive paint Thomsit R762. The mixture was also performed by ultrasonic mixer. From the graph it is known that the $\mathrm{ZnFe}_{2} \mathrm{O}_{4}$ achieved the highest value of the shielding effectiveness. There is an assumption that the shielding effectiveness will increase when the amount of powder increases.

Next measurement was done for the absorption and reflection coefficient. The absorption coefficient of the shielding coatings can be seen in Fig. 3. The highest average value was achieved for $\mathrm{ZnFe}_{2} \mathrm{O}_{4}$ coating. The reflection coefficient of the shielding coatings is shown in Fig. 4. It can be seen that $\mathrm{ZnFe}_{2} \mathrm{O}_{4}$ again achieved the highest average value. 


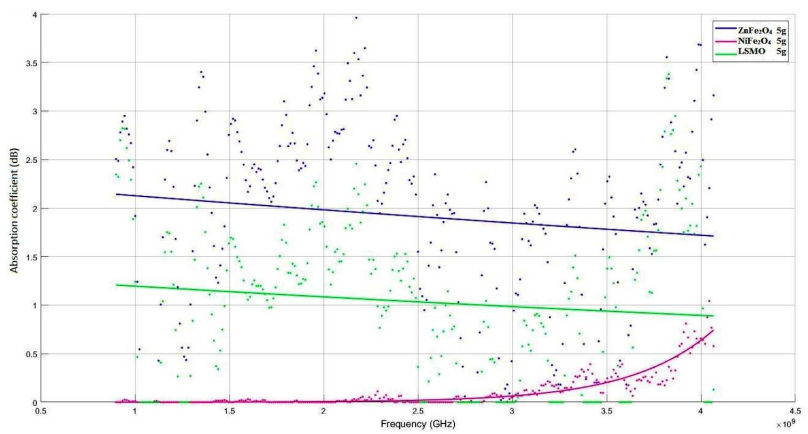

Fig. 3. Dependence of the absorption coefficient on the frequency for the shielding coatings.

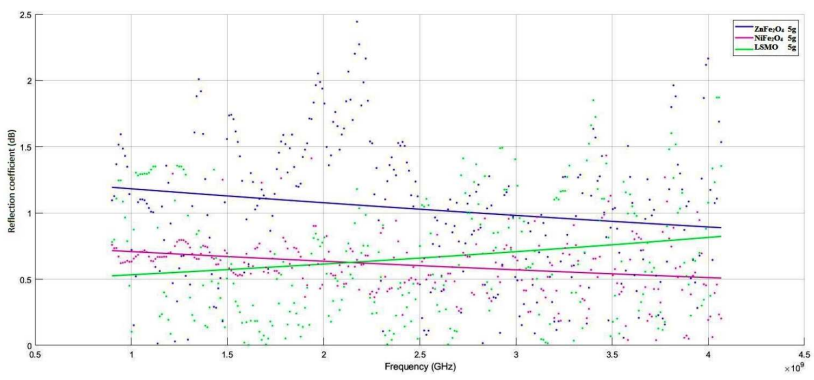

Fig. 4. Dependence of the reflection coefficient on the frequency for the shielding coatings.

\section{Conclusions}

Measurement of shielding effectiveness, absorption and reflection coefficient were done for experimentally developed shielding coatings. Three different experimentally prepared coatings on the surface of the base board were chosen as barriers. Results showed that the coating Thomsit $\mathrm{R} 762+5 \mathrm{~g}$ of $\mathrm{ZnFe}_{2} \mathrm{O}_{4}$ achieved the highest average values of shielding effectiveness, absorption and reflection coefficient. In the future, research would focus on increase of the concentration of conductive parts and thus finding a concentration that would achieve higher $S E$ values, and also finding other combinations of different substances in the coating.

\section{Acknowledgments}

This work was supported by project: Influence of material on electromagnetic field penetration, FEI-201854; Slovak Research and Development Agency under the contract APVV-17-0372; the Scientific Grant Agency of the Ministry of Education of Slovak Republic and the Slovak Academy of Sciences by the projects VEGA No. 1/0435/19; the Cultural and Educational Grant Agency of the Ministry of Education, Science, Research and Sport of the Slovak Republic (KEGA) under the project No. 008TUKE-4/2019.

\section{References}

[1] M. Pavlík, I. Kolcunová, B. Dolník, J. Kurimský, A. Mészáros, D. Medved', M. Kolcun, J. Zbojovský, Acta Electrotechn. Informat. 13, 12 (2013).

[2] B. Shen, Y. Li, D. Yi, W. Zhai, X. Wei, W. Zheng, Carbon 113, 55 (2017).

[3] N. Abbas, H.T. Kim, Macromol. Res. 24, 1084 (2016).

[4] S.C. Lin, C.C.M. Ma, S.T. Hsiao, et al., Appl. Surf. Sci. 385, 436 (2016).

[5] C. Chen, Yu-Sang, Yi-Miao, in: 2017 7th IEEE Int. Symp. on Microwave, Antenna, Propagation, and EMC Technologies (MAPE), Xi'an (China), 2017, p. 336 .

[6] G. Bachir, H. Abdechafik, K. Mecheri, in: 2016 51st Int. Universities Power Engineering Conf. (UPEC), Coimbra (Portugal), 2016, p. 1.

[7] J. Labun, F. Adamcik, M. Ceskovic, "Reflective panel for changing polarization of radio waves, has conductive reflecting surfaces and solid dielectric plate that is positioned to plane of polarization of incident radio wave while frequency is set in UHF control element", Patent Number(s): SK201400053-A3.

[8] M. Krchňák, J. Labun, Application of Depolarization Method in Antenna Technology, Technical University of Košice, 2018 (in Slovak). 